\title{
Hindcast of the 1976/77 and 1998/99 Climate Shifts in the Pacific
}

\author{
HUI DiNG \\ GEOMAR Helmholtz Centre for Ocean Research Kiel, Kiel, Germany \\ RICHARD J. GREATBATCH AND MOJIB LATIF \\ GEOMAR Helmholtz Centre for Ocean Research Kiel and Kiel University, Kiel, Germany \\ WONSUN PARK \\ GEOMAR Helmholtz, Centre for Ocean Research Kiel, Kiel, Germany \\ RÜDIGER GERDES \\ Alfred-Wegener-Institut für Polar- und Meeresforschung, Bremerhaven, Germany
}

(Manuscript received 27 August 2012, in final form 25 March 2013)

\begin{abstract}
The use of a coupled ocean-atmosphere-sea ice model to hindcast (i.e., historical forecast) recent climate variability is described and illustrated for the cases of the 1976/77 and 1998/99 climate shift events in the Pacific. The initialization is achieved by running the coupled model in partially coupled mode whereby global observed wind stress anomalies are used to drive the ocean/sea ice component of the coupled model while maintaining the thermodynamic coupling between the ocean/sea ice and atmosphere components. Here it is shown that hindcast experiments can successfully capture many features associated with the 1976/77 and 1998/99 climate shifts. For instance, hindcast experiments started from the beginning of 1976 can capture sea surface temperature (SST) warming in the central-eastern equatorial Pacific and the positive phase of the Pacific decadal oscillation (PDO) throughout the 9 years following the 1976/77 climate shift, including the deepening of the Aleutian low pressure system. Hindcast experiments started from the beginning of 1998 can also capture part of the anomalous conditions during the 4 years after the 1998/99 climate. The authors argue that the dynamical adjustment of heat content anomalies that are present in the initial conditions in the tropics is important for the successful hindcast of the two climate shifts.
\end{abstract}

\section{Introduction}

Decadal variability is a feature of both the tropical and North Pacific regions (Mantua et al. 1997; Zhang et al. 1997). In the tropical Pacific, decadal variability displays a pattern similar to that associated with El NiñoSouthern Oscillation (ENSO), but with a wider meridional scale and smaller magnitude (Zhang et al. 1997). In the North Pacific, the Pacific decadal oscillation (PDO; Fig. 1a), defined as the first empirical orthogonal function (EOF) of monthly SST anomalies in the Pacific north of $20^{\circ} \mathrm{N}$, has served as a model of climate variability

Corresponding author address: Hui Ding, Duesternbrooker Weg 20, 24105 Kiel, Germany.

E-mail: hding@geomar.de on decadal time scales (Mantua et al. 1997). Previous studies (e.g., Newman et al. 2003) have suggested that the PDO is driven by tropical Pacific variability, although this issue is still controversial. The decadal variability in the Pacific can cause substantial climate changes over North America (Cayan et al. 2001) and impact the biology within the Pacific Ocean with consequences for fisheries (Deser et al. 1996; Mantua et al. 1997). The study of decadal variability in the pan-Pacific is therefore of great socioeconomic interest.

It is well recognized that there were major atmospheric, oceanographic, and ecological changes around 1976/77 (Fig. 1c), termed the 1976/77 climate shift (e.g., Graham 1994; Trenberth and Hurrell 1994; Mantua et al. 1997; Deser et al. 2004; Yeh et al. 2011). After the 1976/77 shift, SST during boreal winter (November-March) was 


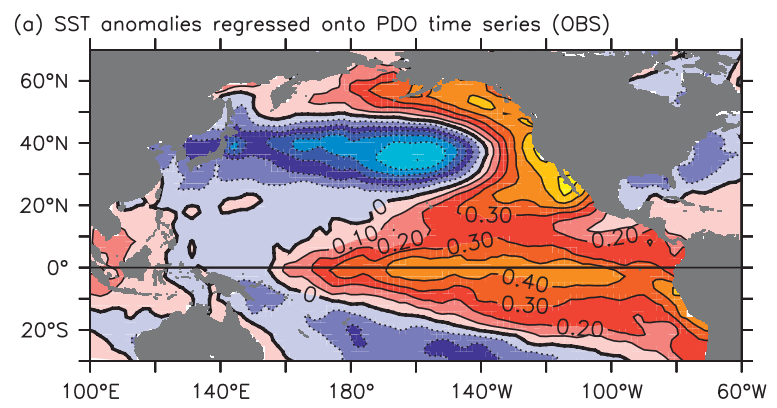

(b) SST onomolies regressed onto PDO time series (Initialisotion)

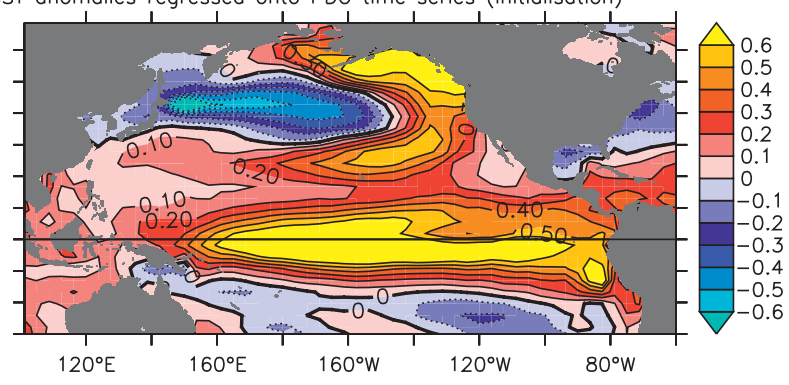

(c) PDO time series from HadISST and initialisation runs
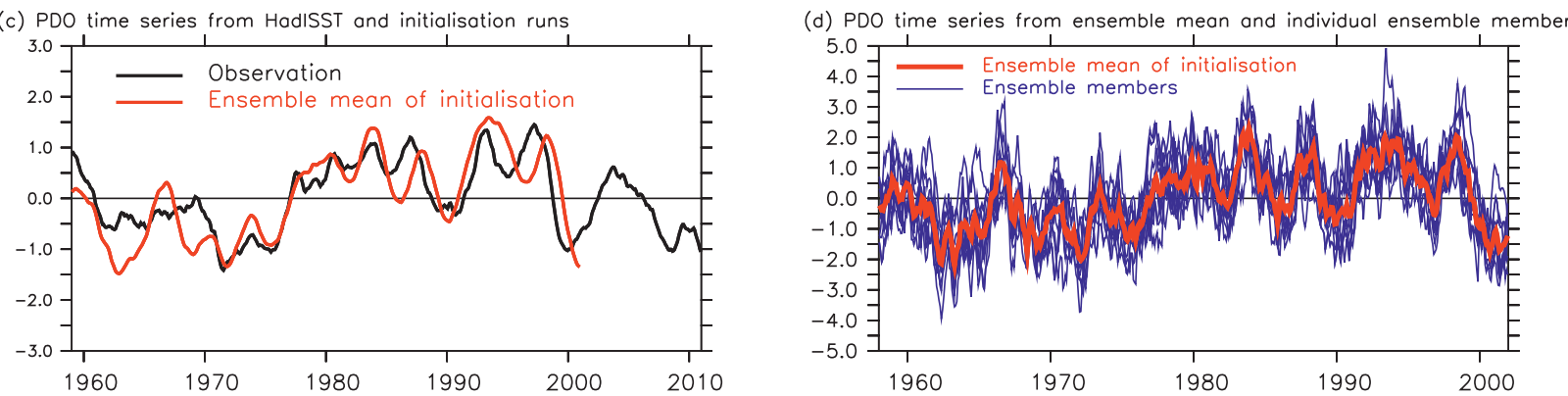

FIG. 1. The SST pattern associated with the PDO (Mantua et al. 1997; Zhang et al. 1997) from (a) observations and (b) the ensemble mean of the initialization runs, in both cases regressed onto the respective principal component (PC) time series associated with the PDO calculated from monthly SST anomalies over the North Pacific $\left(20^{\circ}\right.$ northward). (c) The PC time series associated with the PDO in the observations and the ensemble mean of the initialization runs after a 25-month running mean has been applied. (d) The PDO time series from the ensemble mean (shown in red) and individual ensemble members (shown in blue) of the initialization run (no running mean has been applied). The PDO time series of the individual ensemble members in (d) are derived by projecting the model output onto the SST pattern associated with the PDO shown in (b).

roughly $0.4^{\circ} \mathrm{C}$ warmer (Fig. 2a) over the eastern and central tropical Pacific. The Aleutian low pressure system over the North Pacific was also more intense and shifted slightly eastward (Fig. 2b). The stronger than normal Aleutian low pressure brought more frequent warm and moist air masses to the northeastern Pacific, increasing SST in that area, and also brought more frequent cold air to the middle North Pacific, which, in combination with stronger winds, led to a reduction in the underlying SST. The change in SST induced the transition of the PDO from the negative to the positive phase (Fig. 1).

Recently, some studies reported a possible climate shift around 1998/99 (Fig. 1c; Minobe 2000, 2002). The anomalous conditions during the winter from 1998 through 2002, however, display some features that cannot be strictly characterized by the PDO (Bond et al. 2003). SST (Fig. 3a) was about $0.6^{\circ} \mathrm{C}$ colder in the centraleastern equatorial Pacific and its pattern corresponded roughly to the negative PDO pattern compared to the positive PDO pattern after the 1976/77 climate shift (Fig. 1a). But there were prominent warm SST anomalies over the far western Pacific south of $40^{\circ} \mathrm{N}$ (Fig. 3a) that were not present before or after the 1976/77 climate shift (Bond et al. 2003) and are more in common with the SST pattern associated with the North Pacific Gyre Oscillation (NPGO; Di Lorenzo et al. (2008)) than the PDO. Similarly, the transition between warm and cold SST anomalies in the northwestern Pacific in Fig. 3a is located near $40^{\circ} \mathrm{N}$, again similar to that associated with the NPGO, and farther south than is associated with the PDO. The wintertime sea level pressure (SLP) anomalies (Fig. 3b) were also characterized by a northsouth dipole pattern rather than an overall change in the strength of the Aleutian low. Such a dipole pattern more closely resembles the SLP pattern associated with the North Pacific Oscillation (Rogers 1981; Linkin and Nigam 2008) than the PDO.

Numerous studies (e.g., Jin 2001; White et al. 2003) have commented on the similarity between the characteristics of decadal and interannual variability in the Pacific. Theoretical solutions for tropical ocean dynamics reveal decadal and interannual modes that share the discharge/recharge oscillator mechanism (Jin 1997, 2001). The only difference between decadal and interannual modes is the location of the effective latitude bands of the recharge/discharge of the equatorial heat content by Rossby wave activity (Jin 2001). For the decadal modes, the effective latitude band is at a relatively higher latitude, about $10^{\circ}-20^{\circ}$ from the equator. Rossby waves 
(o) SST (HodISST)

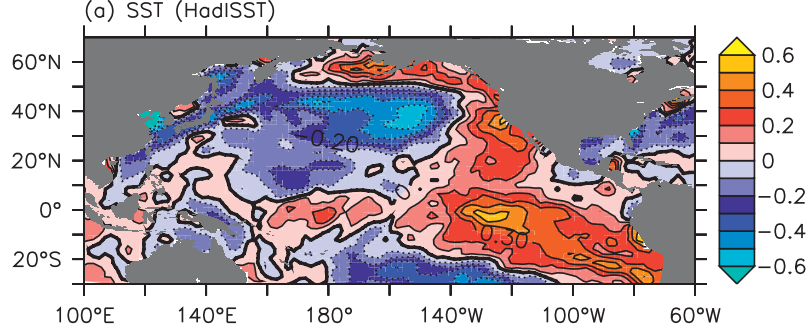

(c) SST (Initialisotion)

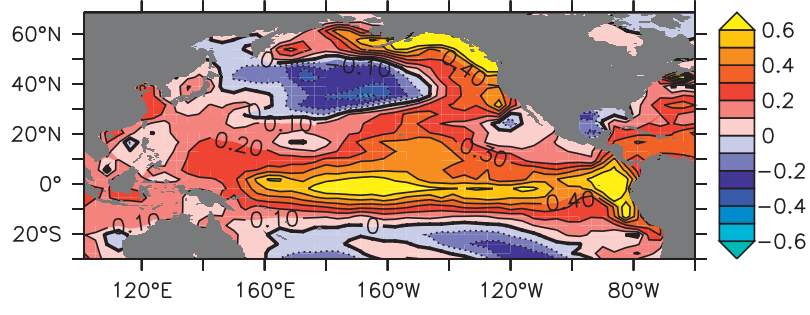

(e) SST (Hindcost)

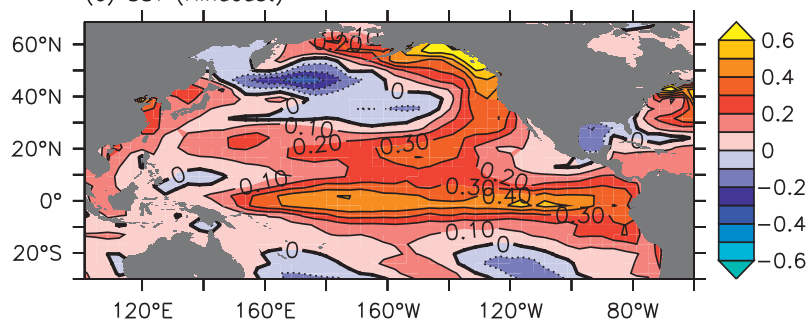

(b) SLP (NCEP)

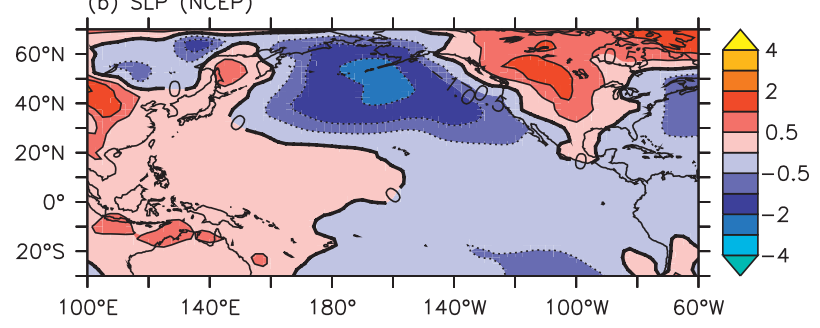

(d) SLP (Initialisation)

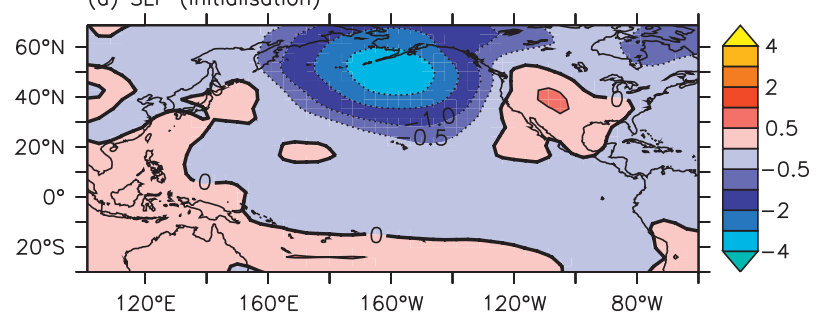

(f) SLP (Hindcast)

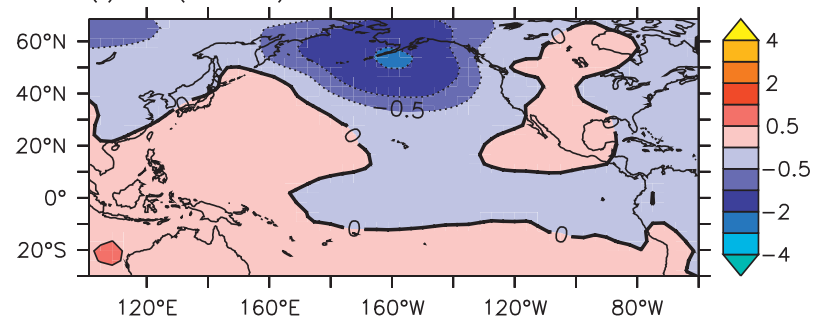

FIG. 2. The anomalous conditions after the 1976/77 climate shift. Spatial anomaly fields of (left) SST and (right) SLP for boreal winter (November-March) of 1976-85 calculated from (a) HadISST, (b) NCEP (Kalnay et al. 1996), (c),(d) the ensemble mean of the initialization runs, and (e),(f) the ensemble mean of the hindcast runs. Contour interval of SST is $0.1^{\circ} \mathrm{C}$. The contours for SLP are $\pm 3, \pm 2, \pm 1$, \pm 0.5 , and $0 \mathrm{hPa}$. The zero contours for both SST and SLP are highlighted. All the major features in the plots from the model runs are significantly different from zero at the $95 \%$ level.

associated with decadal variability in the extratropical Pacific have been found in observations (White et al. 2003) and in ocean models (Capotondi and Alexander 2001). Decadal variability in some coupled climate models is found to have similar dynamical features to the ENSO mode (Knutson and Manabe 1998; Yukimoto et al. 2000).

The similarity in dynamics between decadal and interannual variability in the tropical Pacific noted above suggests that the former is predictable since the latter is predictable (Latif et al. 1998). Recently, several studies have investigated predictability on decadal time scales in the Pacific and Indian Oceans (Mochizuki et al. 2010, 2012; Chikamoto et al. 2012; Kim et al. 2012; Guemas et al. 2013). It is found that the first empirical orthogonal function mode of upper ocean content in the North Pacific is predictable five to six years in advance (note that this mode of variability, while not identical to the PDO, is closely related). In addition, Guemas et al. (2013) find that decadal predictability of Indian Ocean SST is particularly robust and can be attributed to changes in radiative forcing. However, hindcasts (i.e., historical forecasts) focusing on the 1976/77 and possible 1998/99 climate shifts in the Pacific have received less attention [although Chikamoto et al. (2012) discuss the 1998/99 event]. In this study, we attempt to hindcast anomalous conditions associated with these climate shifts-major events associated with decadal variability in the Pacific (Minobe 2000; Deser et al. 2004) — that are potentially more predictable than other smaller-amplitude events. In section 2, the models and the experimental procedure are described. Section 3 presents the model results. Section 4 provides a summary and discussion.

\section{Model and experiments}

In this study, all experiments are based on a coupled atmosphere-ocean-sea ice model: the Kiel Climate Model (KCM; Park et al. 2009). The initialization scheme involves running the $\mathrm{KCM}$ in a partially coupled mode whereby the ocean/sea ice component of $\mathrm{KCM}$ is driven 
(o) SST (HadISST)

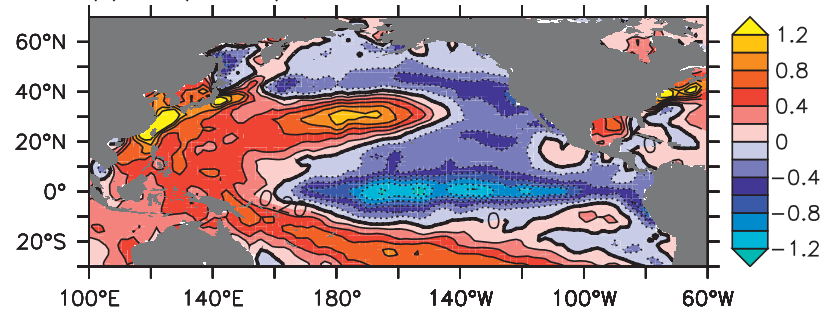

(c) SST (Initiolisation)

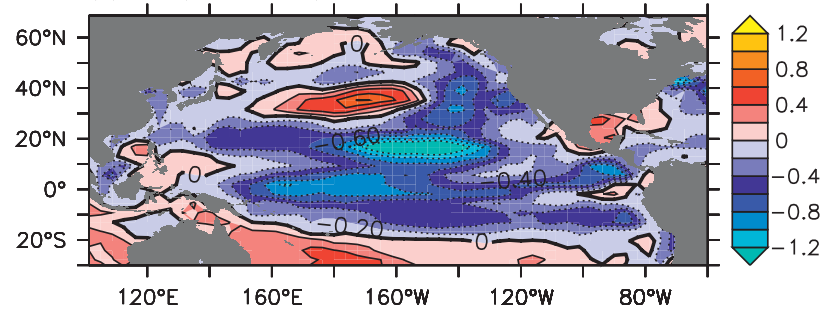

(e) SST (Hindcast)

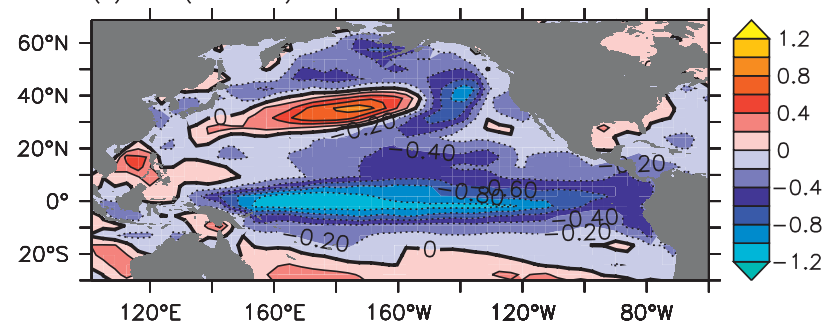

(b) SLP (NCEP)

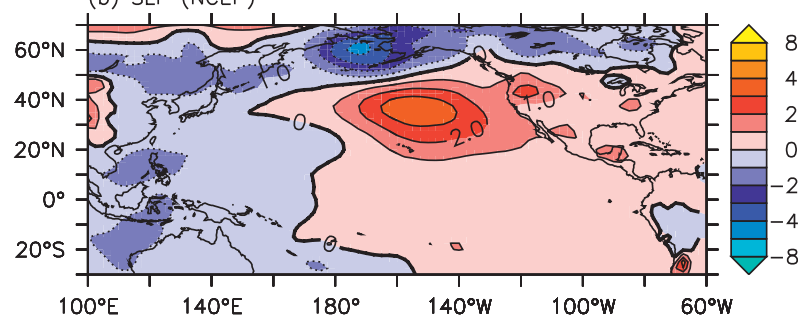

(d) SLP (Initialisotion)

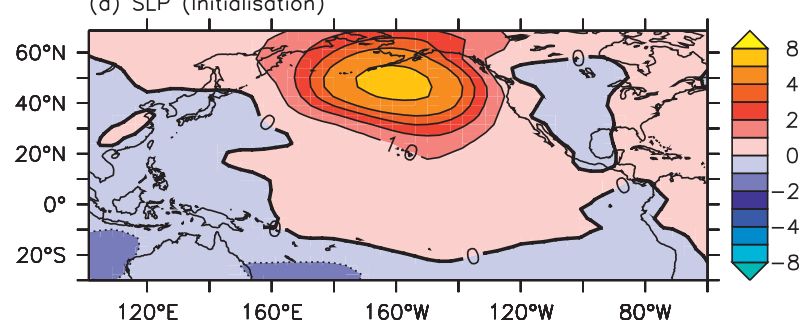

(f) SLP (Hindcast)

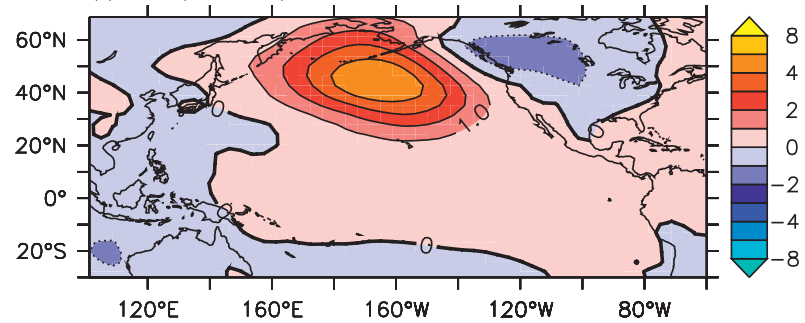

FIG. 3. The anomalous conditions after the 1998/99 climate shift. Spatial anomaly fields of (left) SST and (right) SLP for boreal winter (November-March) of 1998-2002 calculated from (a) HadISST, (b) NCEP (Kalnay et al. 1996), (c),(d) the ensemble mean of the initialisation runs, and (e),(f) ensemble mean of hindcast runs. Contour interval of SST is $0.2^{\circ} \mathrm{C}$. The contours for SLP are $\pm 6, \pm 4, \pm 3, \pm 2, \pm 1$, and $0 \mathrm{hPa}$. The zero contours for both SST and SLP are highlighted. All the major features in the plots from the model runs are significantly different from zero at the $95 \%$ level.

by the time series of observed monthly mean wind stress anomalies added globally to the monthly varying wind stress climatology from the unperturbed KCM, while still maintaining the thermodynamic coupling between the atmospheric and ocean/sea ice components. Thus, SST is a fully prognostic variable and is not directly constrained by observations. Simulations conducted using partial coupling with a coupled model can avoid some of the issues suffered by atmosphere-only or ocean-only simulations. For instance, atmospheric general circulation models (AGCMs) with prescribed SST can exhibit the opposite relationship between rainfall and SST anomalies to that observed over the northwestern tropical Pacific but when the identical AGCM is coupled with an ocean model, the correct rainfall-SST relationship emerges (Wang et al. 2005). In a similar way, oceanonly simulations can also be compromised by the need to specify the atmospheric state (Zhang et al. 1993; Greatbatch et al. 1995; Griffies et al. 2009).
Initialization runs are carried out using both $\mathrm{Na}$ tional Centers for Environmental prediction (NCEP; Kalnay et al. 1996) and 40-yr European Centre for Medium-Range Weather Forecasts (ECMWF) ReAnalysis (ERA-40; Uppala et al. 2005) monthly mean wind stress anomalies from 1948 to 2002 and 1958 to 2002 , respectively. The anomalous wind stress forcing acts to initialize the ocean/sea ice system, a necessary requirement when making decadal predictions (Smith et al. 2007; Keenlyside et al. 2008; Mochizuki et al. 2010, 2012; Chikamoto et al. 2012; Kim et al. 2012; Guemas et al. 2013). Here, wind stress anomalies instead of the full wind stress are employed to avoid drift and coupling shock in the hindcast (i.e., historical forecast) runs. The initialization runs consist of an ensemble of 5 model runs driven by each wind stress product, making 10 model runs in total, differing only in their initial conditions, which are taken from an unperturbed control run of the fully coupled KCM at a time when the coupled 


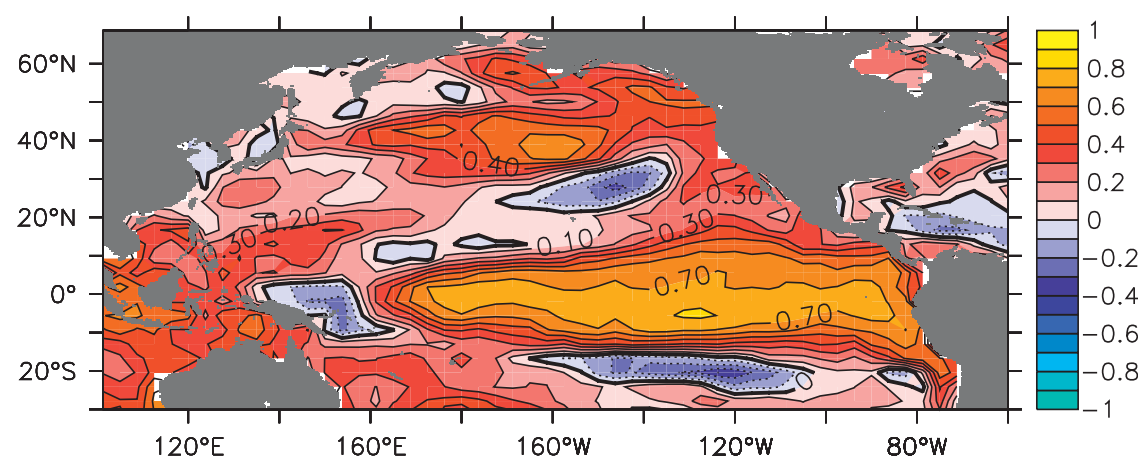

FIG. 4. Correlation between HadISST (Rayner et al. 2003) and model monthly mean SST anomalies for all months from January 1958 to December 2001. The contour interval is 0.1 and the zero contour is highlighted.

model is close to being in equilibrium. Since we focus on the predictability induced only by decadal adjustment through ocean dynamics (Jin 2001; Capotondi and Alexander 2001; White et al. 2003), atmospheric greenhouse gas concentrations are kept fixed throughout the integrations, and there is no account taken of volcanic activity, changes in aerosol concentrations, or solar irradiance change. However, information on all these processes is present in the wind field used to initialize the hindcast runs (see Lu and Zhao 2012). For each of the observations and the initialization runs, anomalies denote the departure from the respective climatological mean state of 1961-2000.

To perform historical forecasts of the 1976/77 and 1998/99 climate shifts, hindcast runs are started from the beginning of 1976 and 1998, respectively, before the climate shifts occurred. In the hindcast runs, the fully coupled model (KCM; Park et al. 2009) is run, initialized from the initialization runs above, and using the same radiative forcing as the initialization runs; in particular, no account is taken of changing greenhouse gas concentrations or variations in aerosol forcing. Each initialization run provides two initial conditions that are slightly different from each other, giving us 20 ensemble members for each hindcast. It is important to note that anomalies calculated from the hindcast runs denote deviations from the climatological mean over the last 300 years of an unperturbed control run of KCM and therefore denotes deviation from the fully coupled model climatology.

\section{Results}

The initialization runs capture the first principal component of observed SST anomalies over the North Pacific (Fig. 1c) and the associated SST variability in the Pacific (Figs. 1a,b). In particular, the initialization runs capture the $1976 / 77$ and $1998 / 99$ climate shifts as revealed by the
PDO time series shown in Fig. 1c. Previous studies (Meehl et al. 2009; Chikamoto et al. 2012) show that changes in external forcing, besides internal variability, play a role in the 1976/77 and 1998/99 climate shifts, an effect not included explicitly in our model. However, as noted earlier, the wind stress forcing prescribed in the initialization runs includes information concerning the change in external forcing (Lu and Zhao 2012). In Fig. 1d we show the PDO time series for the individual ensemble members to give an indication of the spread in the initial conditions used for the hindcasts. It should be noted that the difference between each ensemble member is a result of the variability within the atmosphere model, variability that is not directly constrained in the initialization runs.

The performance of the initialization runs is further assessed by calculating the correlation between model and observed monthly mean SST anomalies (Fig. 4). The model clearly shows skill (correlation as high as 0.7) at reproducing the SST variability in the tropical Pacific and over the North Pacific midlatitudes (0.5-0.6), even though SST is a fully prognostic variable and is not directly constrained by observations. In the tropical Pacific, the high correlation can be understood in terms of the El Niño-Southern Oscillation phenomenon in which wind stress anomalies drive thermocline variability which in turn drives SST variability (Zebiak and Cane 1987; Philander 1990; Jin 1997; Wang 2001; Wang and Picaut 2004). The tropical SST variability drives variability in the Aleutian low pressure system, which in turn drives SST variability in the North Pacific Oceans in the model (not shown), accounting for the good performance of our model in these regions. This is consistent with previous studies (Alexander et al. 2002; Venzke et al. 2000). In the western Pacific, there are some regions where there is no correlation between the observations and the initialization runs (Fig. 4), probably because the external forcing component, which plays a role in 
the SST variability there (Chikamoto et al. 2012), is fixed in the initialization runs.

Turning now to the hindcast runs, historical forecasts started from the beginning of 1976 reproduce the gross features of the SST and SLP signals associated with the 1976/77 climate shift remarkably well (see Fig. 2, and note that all panels refer to anomalies over the 9-yr period 1976-85). Regional details, however, differ. In the tropical Pacific, hindcast runs (Fig. 2e) capture the SST warming in the observations (Fig. 2a) and the initialization runs (Fig. 2c). The hindcast runs (Fig. 2f) also reproduce the deepening of the Aleutian low although with smaller amplitude than seen in NCEP (Fig. 2b) and the initialization runs (Fig. 2d). It is apparent that the tropical Pacific SST warming (Fig. 2e) plays a role in the deepening of the Aleutian low, as seen by comparing the spatial pattern of sea level pressure (Fig. 2f) with the ENSO teleconnection pattern in the model (not shown). The smaller deepening of the Aleutian low in the hindcast runs (Fig. 2f) is probably because SST warming (Fig. 2e) in the hindcast run is smaller than that in the initialization runs in the tropical Pacific. The deeper than normal Aleutian low (Fig. 2f) enhances the cyclonic circulation and the westerly winds over the North Pacific, bringing more frequent warm (cold) air masses from low (high) latitudes and increasing (decreasing) the SST in the eastern (middle) North Pacific (Fig. 2e), consistent with the positive phase of the PDO in the observations (Fig. 2a). It is worthwhile mentioning that the hindcast of the 1976/77 climate shift might be improved by including time-varying greenhouse gas concentrations in the model forcing (Meehl et al. 2009).

We now turn to the hindcast of the 1998/99 climate shift. In general, hindcast runs started from the beginning of 1998 capture some of the signals in SST and SLP (Figs. 3e,f). Hindcast runs reproduce negative SST anomalies in the central-eastern equatorial Pacific and the negative PDO pattern in the North Pacific (Fig. 3e; see also Fig. 5b). But they fail to reproduce positive SST anomalies in the western Pacific to the south of $40^{\circ} \mathrm{N}$ (Fig. 3e). The failure to reproduce the warm SST anomalies in the hindcast and initialization runs can be partly attributed to fixing the atmospheric greenhouse gas concentrations (Chikamoto et al. 2012). Corresponding to the negative SST anomalies in the central-eastern equatorial Pacific, SLP anomalies (Fig. 3f) are characterized by the weakening of the Aleutian low in the North Pacific, with the center of the weakening located right at the zero line of the dipole pattern seen in the observations (Fig. 3b). As noted in the introduction, the SLP pattern seen in the observations closely resembles the SLP pattern associated with the North Pacific Oscillation
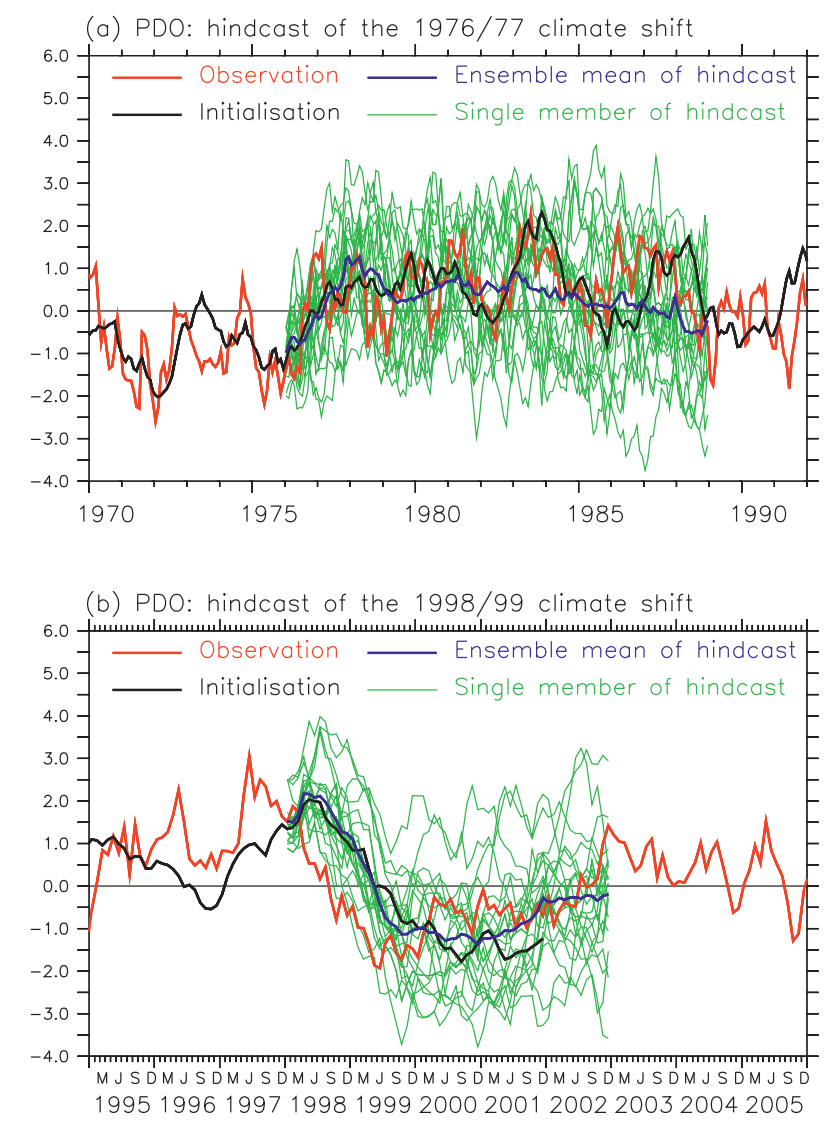

FIG. 5. The PDO time series (monthly means and unfiltered) obtained from the ensemble mean (blue curves) and individual ensemble members (green curves) of the hindcast runs initialized from the beginning of (a) 1976 and (b) 1998, respectively. The PDO time series from the observations (red curves) and the ensemble mean (black curves) of the initialization runs are the unfiltered versions of those shown in Fig. 1c, are also shown for comparison.

(NPO) rather than the pattern associated with the PDO that is seen in the model hindcast and initialization runs. Di Lorenzo et al. (2008) note that of the two centers of action associated with the NPO, the southern center, located near Hawaii, is more closely related to tropical Pacific SST than the northern center over Alaska, a conclusion that is consistent with our results (see also Yeh et al. 2011). Nevertheless, although the hindcast runs cannot capture all the features seen in the observations (Figs. 3a,b), they do exhibit similar SST and SLP patterns to those in the initialization runs (Figs. 3c,d). This implies the role of memory present in the initialization runs for determining at least some of the wintertime anomalies from 1998 through 2002.

To gain some idea of the uncertainty in the model hindcasts, Fig. 5 shows the monthly time series of the PDO from each of the ensemble members (shown in green), the ensemble mean (shown in blue), the ensemble 
mean of the initialization runs (shown in black), and the observations (shown in red) (the last two curves are the unfiltered versions of the curves shown in Fig. 1c). It is clear that the ensemble members have considerable spread around the ensemble mean. A Student's $t$ test applied to each month separately shows that, in the case of the 1976/77 hindcast, the ensemble mean is significantly different from zero ${ }^{1}$ at the $95 \%$ level throughout the 9 year period starting during 1977 and ending in 1985, apart from a gap in 1979 and the first part of 1980 when the ensemble mean index dips toward zero and the significance level drops to $80 \%$. Likewise for the 1998/99 event, once the ensemble mean index for the hindcast runs becomes negative, it remains negative and statistically significantly different from zero at the $95 \%$ level. In the case of the 1976/77 hindcast, the initial rise in the index is clearly captured, and in the case of the 1998/99 hindcast, following an initial rise, there is a clear drop in the ensemble mean index during the first two years of the hindcast, a drop that is delayed compared to the observations. This drop in the index is also is very clear in the ensemble members. It is also likely that the slow decline in the index that can be seen in the ensemble mean in the 1976/77 hindcast, following the initial peak, would not be so strong if changing radiative forcing were included in the model runs (Meehl et al. 2009). We also note that the spread between the ensemble members is established early in the integrations. As noted when discussing Fig. 1d, there is already considerable spread in the initial conditions used for the hindcasts and, not surprisingly, the spread is bigger in the (fully unconstrained) hindcast runs.

Rossby waves in the extratropical Pacific play an important role in the discharge/recharge mechanism associated with tropical Pacific decadal variability (e.g., Jin 2001; Capotondi and Alexander 2001; White et al. 2003), and it is of interest to see if westward propagating features, resembling Rossby waves, also play a role in our model runs. Figure 6 shows upper ocean heat content from the initialization runs for each of the latitude bands $15^{\circ}-20^{\circ} \mathrm{N}$ and $15^{\circ}-20^{\circ} \mathrm{S}$. Westward propagating disturbances can clearly be seen in both hemispheres. Of particular interest are the positive heat content anomalies that spread westward and originate around 1970 near $120^{\circ} \mathrm{W}$ in both hemispheres. After intersecting the western boundary, these anomalies subsequently spread across the equator in the late 1970s, as can be seen in Fig. 7a (to be discussed further later). The heat content anomalies in the Southern Hemisphere are

\footnotetext{
${ }^{1}$ As noted earlier, the reference is the coupled model climatology.
}

similar to the subsurface temperature anomalies that were reported by Giese et al. (2002) as precursors of the 1976/77 climate shift. Similar heat content anomalies, this time of the opposite sign, can be seen in the run up to the $1998 / 99$ event, again originating near $120^{\circ} \mathrm{W}$, especially in the Northern Hemisphere where the correspondence to the opposite signed anomalies in the early 1970s is clearer. There also appear to be negative heat content anomalies that propagate westward in both hemispheres in the mid-1980s and that may have been precursors of the drop in the PDO index around 1985 (see Fig. 1c).

Also shown in Fig. 6 are the anomalies in Ekman pumping [see Eq. (9.4.2) in Gill 1982] in the same latitude bands. These show negative (downward)/positive (upward) Ekman pumping anomalies, especially on the eastern side of the sections, associated with the positive/ negative heat flux anomalies and suggesting the anomalies in Ekman pumping play a role in driving the heat content anomalies, although the exact causal connection between the two clearly requires further investigation, beyond the scope of the present study. The phase speed of the westward propagating anomalies in the heat content is estimated to be around $11 \mathrm{~cm} \mathrm{~s}^{-1}$. This is a bit slower than the phase speed $\left(13 \mathrm{~cm} \mathrm{~s}^{-1}\right)$ in Capotondi and Alexander (2001) and also slower than the phase speed of the first mode unforced baroclinic Rossby waves $\left(15-16 \mathrm{~cm} \mathrm{~s}^{-1}\right)$ at these latitudes. This could be because higher baroclinic modes play a role ( $\mathrm{Wu}$ et al. 2003) or it could be because of a feedback between the heat content anomalies and the overlying atmosphere [see, e.g., Philander et al. (1984) and note how the Ekman pumping anomalies sometimes seem to propagate westward with the heat content anomalies].

When the hindcast runs are started from the beginning of 1976, the westward propagating heat content anomalies, resembling Rossby waves between $15^{\circ}$ and $20^{\circ}$ of the equator (Fig. 6), are present in the initial conditions. Since the success of the hindcasts depends on the information in the initial conditions (there are no changes in radiative forcing included in the hindcast runs), we argue that the subsequent evolution of these features in the hindcast runs is the reason the hindcast runs are able to capture the SST anomalies shown in Fig. 2e. A similar origin for the 1976/77 climate shift has been argued by Giese et al. (2002). Figure 7 shows that once the positive heat content anomalies reach the western boundary, they spread eastward along the equator in both the ensemble mean of the initialization runs (Fig. 7a) and in the ensemble mean of the hindcast runs (Fig. 7b; see the positive heat content anomalies in both Figs. $7 \mathrm{a}$ and $7 \mathrm{~b}$ in the late 1970s). In the ensemble mean of the hindcast runs, the subsequent evolution of heat 
(o) $\mathrm{HC} 300 \mathrm{~m}(15 \mathrm{~N}-20 \mathrm{~N})$

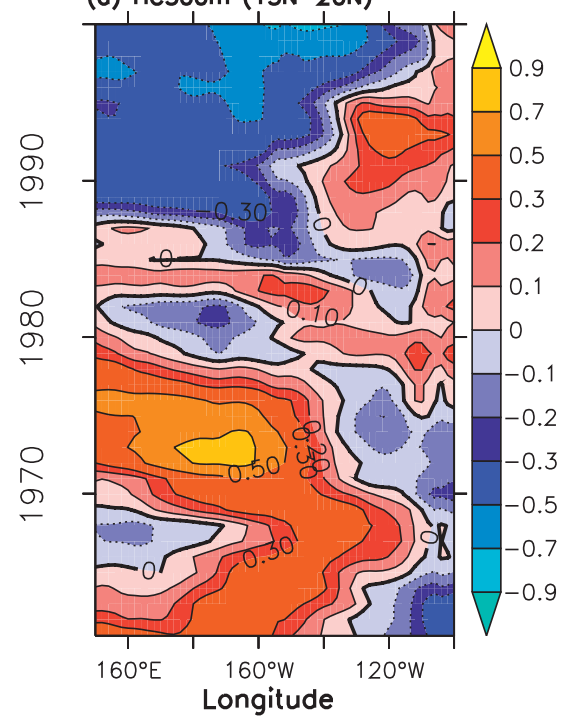

(c) HC300m (20S-15S)

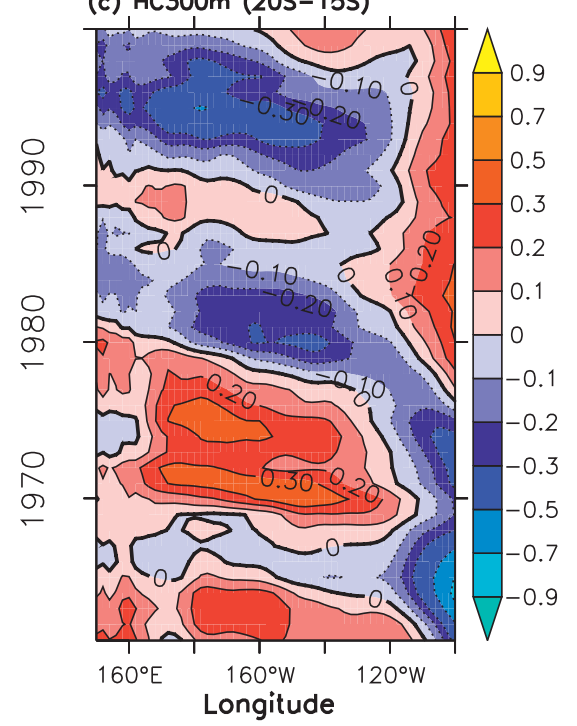

(b) $w_{E}(15 N-20 N)$

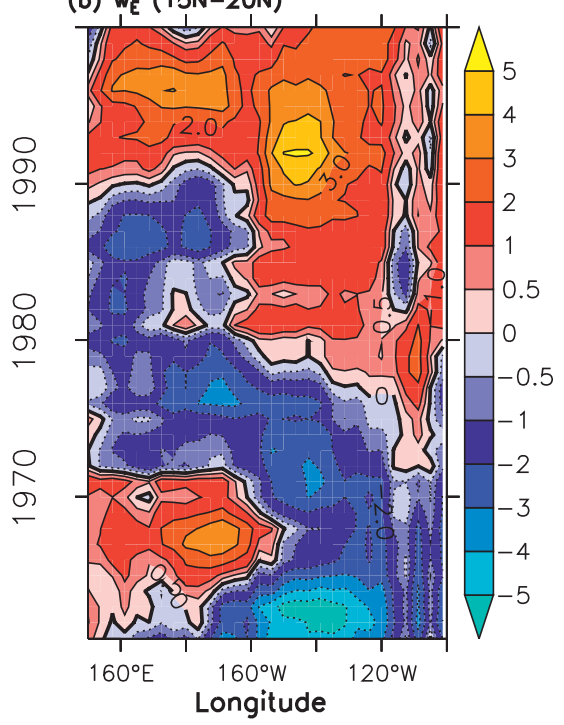

(d) $w_{E}(20 S-15 S)$

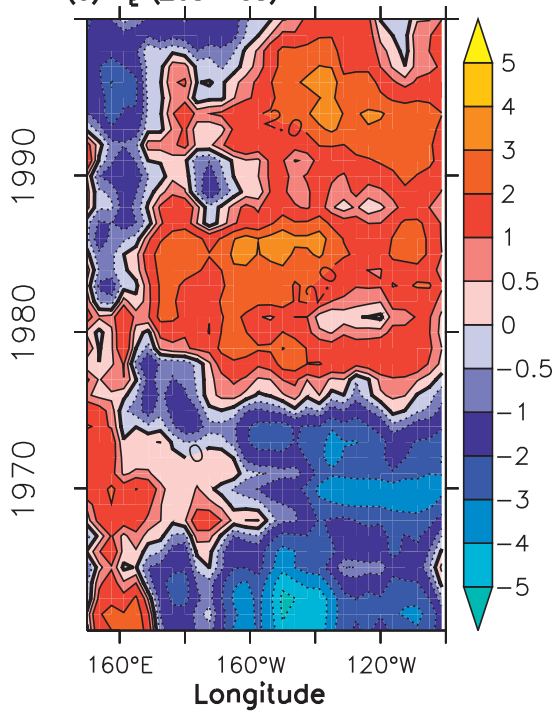

FIG. 6. (a),(c) Heat content anomalies and (b),(d) Ekman pumping velocity anomalies as a function of longitude and time averaged over (top) $20^{\circ}-15^{\circ} \mathrm{S}$ and (bottom) $15^{\circ}-20^{\circ} \mathrm{N}$, respectively. Here, ocean temperature anomalies averaged from the surface to $300-\mathrm{m}$ depth have been used to represent heat content anomalies. A 5-yr running mean has been employed to remove the ENSO signals. The unit for heat content anomalies is ${ }^{\circ} \mathrm{C}$, and the zero contour is highlighted. The unit for Ekman pumping velocity anomalies is $10^{-5} \mathrm{~cm} \mathrm{~s}^{-1}$. The heat content anomalies are taken from the ensemble mean of the initialization runs, and the Ekman pumping velocity anomalies are calculated from the average of the NCEP (Kalnay et al. 1996) and ERA-40 (Uppala et al. 2005) wind stress anomalies using Eq. (9.4.2) in Gill (1982) (note that positive/negative indicates upward/downward Ekman pumping anomalies).

content anomalies both on (Fig. 7b) and off (Fig. 8b) the equator is smeared out by the averaging across different ensemble members. However, looking at the heat content anomalies in individual ensemble members (Figs. $7 \mathrm{c}, \mathrm{d}$ and $8 \mathrm{c}, \mathrm{d}$ show examples), we see features very similar to those in the ensemble mean of the initialization runs (Figs. 7a and 8a). Nevertheless, the timing of these events differs in the different ensemble members of the hindcast, leading to the smeared picture in the ensemble mean. It is nevertheless remarkable that the 
(a) Ensemble mean of Initialisation

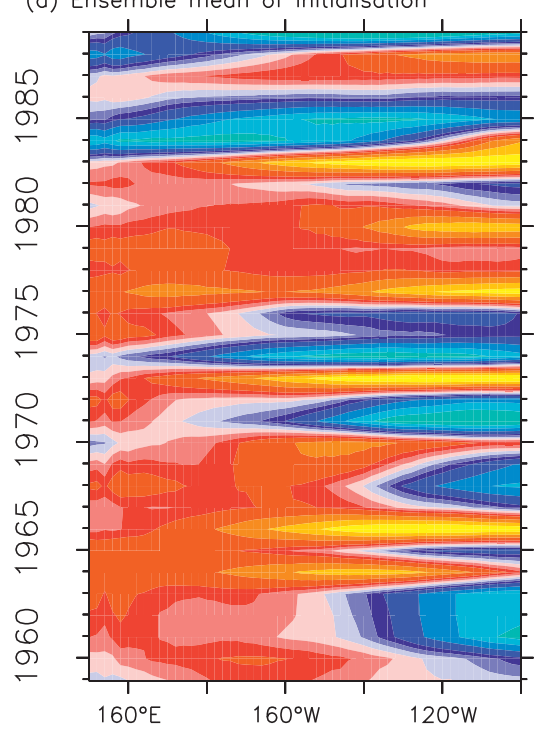

(c) One member of Hindcast + Initialisation

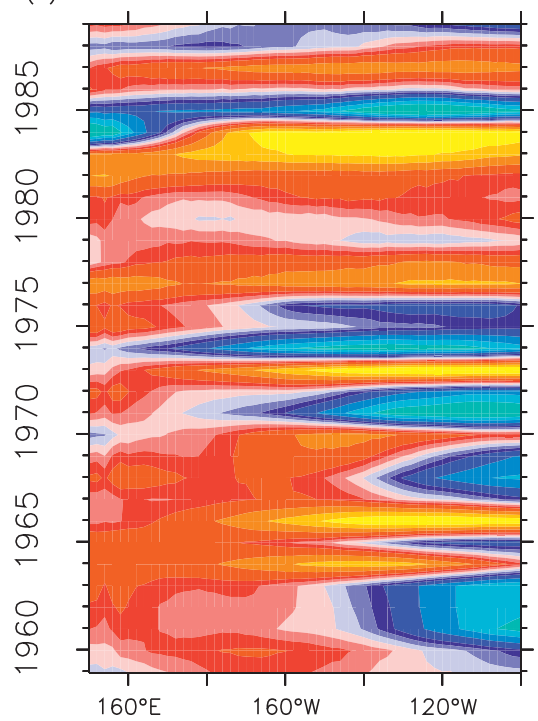

(b) Ensemble mean of Hindcast + Initialisation

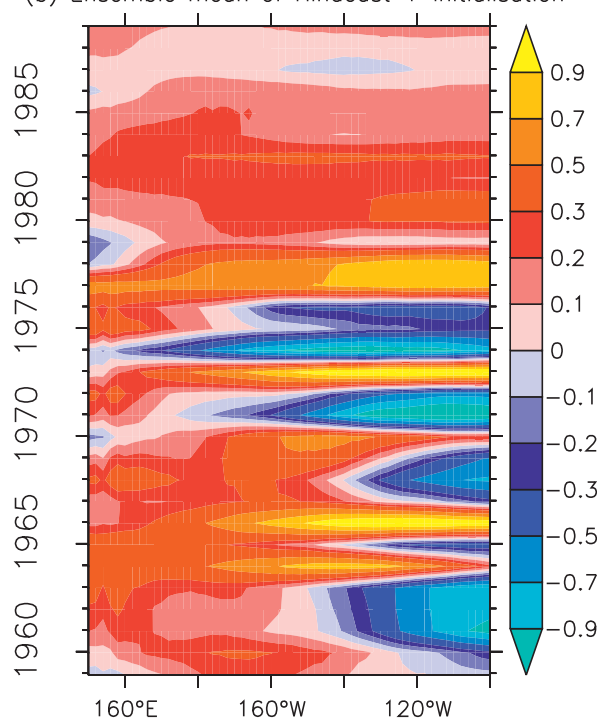

(d) One member of Hindcast + Initialisation

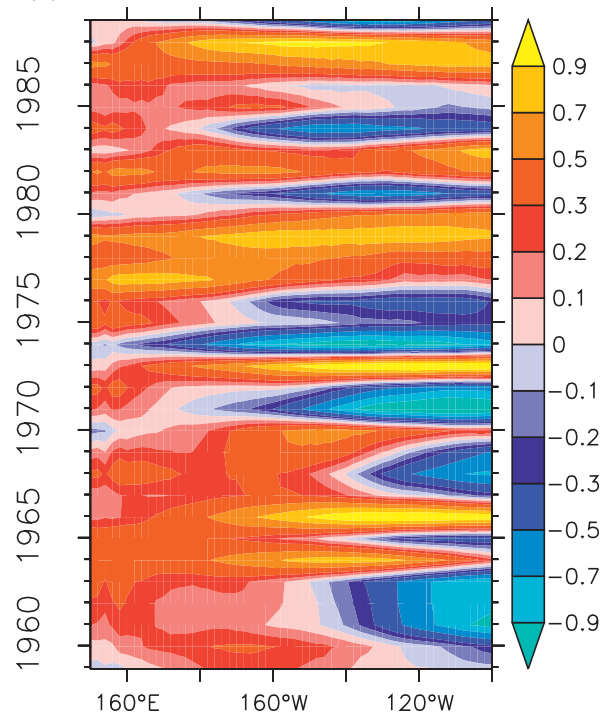

FIG. 7. Heat content anomalies, as in Fig. 6, but here along the equator in (a) the ensemble mean of the initialization runs, (b) the ensemble mean of the hindcast runs initialized in 1976 (the ensemble mean of the initialization runs is shown before 1976), and (c),(d) two individual ensemble members from the hindcast (the ensemble mean of the initialization runs is shown before 1976). Here no running mean filter has been used.

ensemble mean of the PDO index in the hindcast remains positive ${ }^{2}$ throughout the period from 1977 to 1985, as noted earlier when discussing Fig. 5a, indicating that a decadal adjustment process in taking place in the coupled model following the initialization of the hindcast runs. Understanding the details of this decadal

\footnotetext{
${ }^{2}$ As noted earlier, the reference state is the coupled model climatology.
}

adjustment process is beyond the scope of the present paper but is fundamental to understanding the dynamics of the PDO. Finally we note that making the same figures from the 1998/99 hindcast leads to the same conclusions and we do not shown these figures here.

\section{Summary and discussion}

In this study we present results using a fully coupled atmosphere-ocean-sea ice model [the Kiel Climate Model 

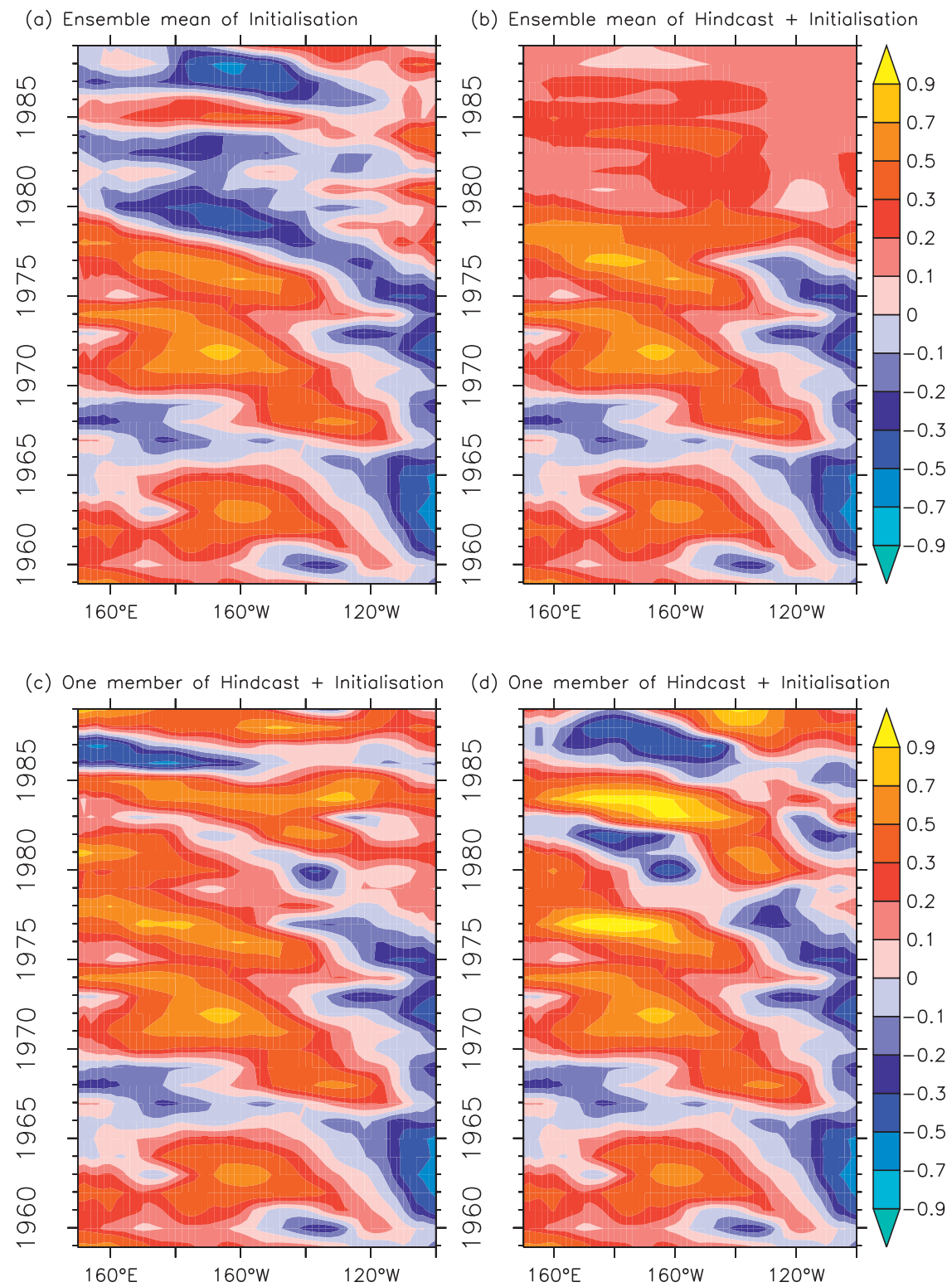

FIG. 8. As in Fig. 7, but averaged over the latitude bands $15^{\circ}-20^{\circ} \mathrm{N}$ and $15^{\circ}-20^{\circ} \mathrm{S}$.

(KCM); Park et al. 2009] to hindcast (i.e., historically forecast) the 1976/77 and 1998/99 climate shifts in the Pacific region. The hindcast runs are initialized using a partial coupling technique applied to the coupled model whereby the ocean/sea ice component of the KCM sees the time series of observed monthly mean wind stress anomalies that are added globally to the wind stress climatology from a control run using the coupled KCM. One advantage of this strategy is that SST is a fully prognostic variable and can freely interact with the atmospheric component of the coupled model. Hindcast experiments are started from initial conditions provided by the initialization runs and since only wind stress anomalies are used for the initialization, there is very little coupling shock at the start of the hindcast runs. Analysis of the hindcast experiments shows that they can successfully capture many features of the anomalous conditions after the two climate shifts. For example, hindcast experiments started from the beginning of 1976 can capture SST warming in the central-eastern equatorial Pacific and the positive phase of the Pacific decadal oscillation (PDO) throughout the 9 years following after the 1976/77 climate shift, including the deepening of the Aleutian low pressure system. Hindcast experiments started from the beginning of 1998 can also capture part of the anomalous conditions during 
the 4 years after the 1998/99 climate. We have argued that decadal adjustment in the tropical Pacific Ocean provides the memory enabling the successful hindcasts of the two climate shifts.

We noted in the introduction that the anomalous conditions after the 1998/99 climate shift have features in common with the North Pacific Oscillation (NPO; Rogers 1981; Linkin and Nigam 2008) in the atmosphere and the North Pacific Gyre Oscillation (NPGO; Di Lorenzo et al. 2008) in the ocean. The NPO and the NPGO are associated with the second EOF of winter monthly mean SLP and SST over the North Pacific whereas the PDO is associated with the first EOF of winter monthly mean SST over the North Pacific. The failure of the hindcast of the NPO-like SLP pattern after the 1998/99 climate shift, despite the successfully initialized tropical SST anomalies, seems to suggest that the tropical SST variability plays a secondary role for the variability associated with the NPO, especially the northern center of action, consistent with Di Lorenzo et al. (2008) and Yeh et al. (2011). Overall, our results suggest that capturing the NPO and NPGO modes in hindcast mode is more difficult than capturing the PDO, at least for the coupled model we have used here (the KCM), a topic for future research.

Hindcast runs initialized between 1977 and 1997 are generally less successful than we have shown here, consistent with Kim et al. (2012), who conclude that decadal predictability in the North Pacific basin is relatively low. However, we argue that this is at least partly because the PDO exhibited no major transitions during this time period. We argue that predictive skill is likely to be enhanced during times when modes of variability such as the PDO are in transition (Fig. 1c), with reduced skill at other times. A similar argument has been made regarding predictability in the North Atlantic sector (Eden et al. 2002). This suggests that traditional skill measures such as anomaly correlation may miss the enormous multiyear predictability potential which occasionally exists. We also note that because our hindcasts are capturing transitions in the PDO index, forecasts based on persistence would be very poor by comparison. Finally we note that whereas decadal predictability studies have generally focused on predictability arising from the decadal time scale adjustment of the North Atlantic (Smith et al. 2007; Keenlyside et al. 2008), here we show hindcast skill arising from the decadal adjustment of the tropical Pacific.

Acknowledgments. We very much appreciate the comments by the three anonymous reviewers and the editor, Dr. Timothy DelSole. These comments led to a significant improvement in the manuscript. This work has been funded by the BMBF MiKlip Project MODINI, EU-THOR project (Grant Agreement GA212643), and GEOMAR. We are grateful to the Rechnenzentrum of Universität Kiel for the use of computer time. Figures were created using Ferret, a product of NOAA's Pacific Marine Environmental Laboratory.

\section{REFERENCES}

Alexander, M., I. Bladé, M. Newman, J. Lanzante, N. Lau, and J. Scott, 2002: The atmospheric bridge: The influence of ENSO teleconnections on air-sea interaction over the global oceans. J. Climate, 15, 2205-2231.

Bond, N., J. Overland, M. Spillane, and P. Stabeno, 2003: Recent shifts in the state of the North Pacific. Geophys. Res. Lett., 30, 2183, doi:10.1029/2003GL018597.

Capotondi, A., and M. Alexander, 2001: Rossby waves in the tropical North Pacific and their role in decadal thermocline variability. J. Phys. Oceanogr., 31, 3496-3515.

Cayan, D., S. Kammerdiener, M. Dettinger, J. Caprio, and D. Peterson, 2001: Changes in the onset of spring in the western United States. Bull. Amer. Meteor. Soc., 82, 399-415.

Chikamoto, Y., and Coauthors, 2012: Predictability of a stepwise shift in Pacific climate during the late 1990s in hindcast experiments using MIROC. J. Meteor. Soc. Japan, 90A, 1-21, doi:10.2151/jmsj.2012-A01.

Deser, C., M. Alexander, and M. Timlin, 1996: Upper-ocean thermal variations in the North Pacific during 1970-1991. J. Climate, 9, 1840-1855.

$\ldots$, A. Phillips, and J. Hurrell, 2004: Pacific interdecadal climate variability: Linkages between the tropics and the North Pacific during boreal winter since 1900. J. Climate, 17, 3109-3124.

Di Lorenzo, E., and Coauthors, 2008: North Pacific Gyre Oscillation links ocean climate and ecosystem change. Geophys. Res. Lett., 35, L08607, doi:10.1029/2007GL032838.

Eden, C., R. Greatbatch, and J. Lu, 2002: Prospects for decadal prediction of the North Atlantic Oscillation (NAO). Geophys. Res. Lett., 29 (10), doi:10.1029/2001GL014069.

Giese, B., S. Urizar, and N. Fuckar, 2002: Southern Hemisphere origins of the 1976 climate shift. Geophys. Res. Lett., 29 (2), doi:10.1029/2001GL013268.

Gill, A., 1982: Atmosphere-Ocean Dynamics. International Geophysics Series, Vol. 30, Academic Press, 662 pp.

Graham, N., 1994: Decadal-scale climate variability in the tropical and North Pacific during the 1970s and 1980s: Observations and model results. Climate Dyn., 10, 135-162, doi:10.1007/ BF00210626.

Greatbatch, R., G. Li, and S. Zhang, 1995: Hindcasting ocean climate variability using time-dependent surface data to drive a model: An idealized study. J. Phys. Oceanogr., 25, 27152725.

Griffies, S., and Coauthors, 2009: Coordinated ocean-ice reference experiments (COREs). Ocean Modell., 26, 1-46, doi:10.1016/ j.ocemod.2008.08.007.

Guemas, V., S. Corti, J. García-Serrano, F. Doblas-Reyes, M. Balmaseda, and L. Magnusson, 2013: The Indian Ocean: The region of highest skill worldwide in decadal climate prediction. J. Climate, 26, 726-739.

Jin, F., 1997: An equatorial ocean recharge paradigm for ENSO. Part I: Conceptual model. J. Atmos. Sci., 54, 811-829.

- 2001: Low-frequency modes of tropical ocean dynamics. J. Climate, 14, 3874-3881. 
Kalnay, E., and Coauthors, 1996: The NCEP/NCAR 40-Year Reanalysis Project. Bull. Amer. Meteor. Soc., 77, 437-471.

Keenlyside, N., M. Latif, J. Jungclaus, L. Kornblueh, and E. Roeckner, 2008: Advancing decadal-scale climate prediction in the North Atlantic sector. Nature, 453, 84-88, doi:10.1038/nature06921.

Kim, H., P. Webster, and J. Curry, 2012: Evaluation of short-term climate change prediction in multi-model CMIP5 decadal hindcasts. Geophys. Res. Lett., 39, L10701, doi:10.1029/ 2012 GL051644.

Knutson, T., and S. Manabe, 1998: Model assessment of decadal variability and trends in the tropical Pacific Ocean. J. Climate, 11, 2273-2296.

Latif, M., and Coauthors, 1998: A review of the predictability and prediction of ENSO. J. Geophys. Res., 103, 14375-14393.

Linkin, M., and S. Nigam, 2008: The North Pacific Oscillation-west Pacific teleconnection pattern: Mature-phase structure and winter impacts. J. Climate, 21, 1979-1997.

Lu, J., and B. Zhao, 2012: The oceanic feedback in the climate response to doubling $\mathrm{CO}_{2}$. J. Climate, 25, 7544-7563.

Mantua, N., S. Hare, Y. Zhang, J. Wallace, and R. Francis, 1997: A Pacific interdecadal climate oscillation with impacts on salmon production. Bull. Amer. Meteor. Soc., 78, 1069-1079.

Meehl, G., A. Hu, and B. Santer, 2009: The mid-1970s climate shift in the Pacific and the relative roles of forced versus inherent decadal variability. J. Climate, 22, 780-792.

Minobe, S., 2000: Spatio-temporal structure of the pentadecadal variability over the North Pacific. Prog. Oceanogr., 47, 381408, doi:10.1016/S0079-6611(00)00042-2.

_ 2002: Interannual to interdecadal changes in the Bering Sea and concurrent 1998/99 changes over the North Pacific. Prog. Oceanogr., 55, 45-64, doi:10.1016/S0079-6611(02)00069-1.

Mochizuki, T., and Coauthors, 2010: Pacific decadal oscillation hindcasts relevant to near-term climate prediction. Proc. Natl. Acad. Sci. USA, 107, 1833-1837, doi:10.1073/pnas.0906531107.

_ - and Coauthors, 2012: Decadal prediction using a recent series of MIROC global climate models. J. Meteor. Soc. Japan, 90, 373-383, doi:10.2151/jmsj.2012-A22.

Newman, M., G. Compo, and M. Alexander, 2003: ENSO-forced variability of the Pacific decadal oscillation. J. Climate, 16, 3853-3857.

Park, W., N. Keenlyside, M. Latif, A. Stroeh, R. Redler, E. Roeckner, and G. Madec, 2009: Tropical Pacific climate and its response to global warming in the Kiel Climate Model. J. Climate, 22, 71-92.

Philander, S., 1990: El Niño, La Niña, and the Southern Oscillation. Academic Press, 293 pp.

, T. Yamagata, and R. Pacanowski, 1984: Unstable air-sea interactions in the tropics. J. Atmos. Sci., 41, 604-613.
Rayner, N., D. Parker, E. Horton, C. Folland, L. Alexander, D. Rowell, E. Kent, and A. Kaplan, 2003: Global analyses of sea surface temperature, sea ice, and night marine air temperature since the late nineteenth century. J. Geophys. Res., 108, 4407, doi:10.1029/2002JD002670.

Rogers, J., 1981: The North Pacific Oscillation. J. Climatol., 1, 39-57, doi:10.1002/joc.3370010106.

Smith, D., S. Cusack, A. Colman, C. Folland, G. Harris, and J. Murphy, 2007: Improved surface temperature prediction for the coming decade from a global climate model. Science, 317, 796-799, doi:10.1126/science.1139540.

Trenberth, K., and J. Hurrell, 1994: Decadal atmosphere-ocean variations in the Pacific. Climate Dyn., 9, 303-319, doi:10.1007/ BF00204745.

Uppala, S., and Coauthors, 2005: The ERA-40 Re-Analysis. Quart. J. Roy. Meteor. Soc., 131, 2961-3012, doi:10.1256/qj.04.176.

Venzke, S., M. Latif, and A. Villwock, 2000: The coupled GCM ECHO-2. Part II: Indian Ocean response to ENSO. J. Climate, 13, 1371-1383.

Wang, B., Q. Ding, X. Fu, I. Kang, K. Jin, J. Shukla, and F. DoblasReyes, 2005: Fundamental challenge in simulation and prediction of summer monsoon rainfall. Geophys. Res. Lett., 32, L15711, doi:10.1029/2005GL022734.

Wang, C., 2001: A unified oscillator model for the El NiñoSouthern Oscillation. J. Climate, 14, 98-115.

— view. Earth's Climate: The Ocean-Atmosphere Interaction, Geophys. Monogr., Vol. 147, Amer. Geophys. Union, 21-48.

White, W., Y. Tourre, M. Barlow, and M. Dettinger, 2003: A delayed action oscillator shared by biennial, interannual, and decadal signals in the Pacific Basin. J. Geophys. Res., 108, 3070, doi:10.1029/2002JC001490.

Wu, L., Z. Liu, R. Gallimore, R. Jacob, D. Lee, and Y. Zhong, 2003: Pacific decadal variability: The tropical Pacific mode and the North Pacific mode. J. Climate, 16, 1101-1120.

Yeh, S., Y. Kang, Y. Noh, and A. Miller, 2011: The North Pacific climate transitions of the winters of $1976 / 77$ and $1988 / 89$. J. Climate, 24, 1170-1183.

Yukimoto, S., M. Endoh, Y. Kitamura, A. Kitoh, T. Motoi, and A. Noda, 2000: ENSO-like interdecadal variability in the Pacific Ocean as simulated in a coupled general circulation model. J. Geophys. Res., 105 (C6), 13 945-13963.

Zebiak, S., and M. Cane, 1987: A model El Niño-Southern Oscillation. Mon. Wea. Rev., 115, 2262-2278.

Zhang, S., R. Greatbatch, and C. Lin, 1993: A reexamination of the polar halocline catastrophe and implications for coupled ocean-atmosphere modeling. J. Phys. Oceanogr., 23, 287-299.

Zhang, Y., J. Wallace, and D. Battisti, 1997: ENSO-like interdecadal variability: 1900-93. J. Climate, 10, 1004-1020. 